\title{
Paradox of "Progress": The Role of Western Education in the Transformation of the Family in Nigeria
}

\author{
Adewale Rotimi \\ Department of Sociology/Anthropology, Obafemi Awolowo University, Ile-Ife, Nigeria \\ E-mail: walerotimi1987@yahoo.com
}

KEYWORDS Family. Western Education. Transformation. Role. Socialization. Dual Career. Extended Family.

\begin{abstract}
The paper has identified the roles which western education has played in transforming the traditional family in Nigeria. However, this transformation which has been viewed as "progress" from western perspectives, has also produced some unintended circumstances. Those aspects of the family most affected by change include, the extended family system, mate selection, division of labour within the family, patriarchal authority and the socialization process. Under the modern nuclear family system, the individuals are no more burdened by responsibilities to others who are outside the nuclear family. Mate selection has become more liberalized with individual young men and women free to choose their own partners. Because husbands and wives both now have careers outside the home, domestic decisions have become more democratizd and husbands are no more the fountain of authority. Socialization of children in the home is complemented by other agents outside the home; schools, peer groups the mass media, just to mention a few have also become agents of socialization. It is however, a paradox that the changes outlined above have also produced some unintended consequences which have negatively affected the modern Nigerian family. For example, the demise of the extended family system also means the loss of social and economic safety nets to which many people used to fall during periods of adversity. Mate selection has become so liberalized and sophisticated that many people have decided to either postpone or delay marriage. In some cases, lack of support in mate selection from parents of couples has made divorce very rampant. Where both husbands and wives have their careers and they both bring income to the family, the locus of authority has shifted from the man. Occasionally one of the couples has had to relocate or transfer to a different part of the country. This has affected joint socialization of children. Occasionally cases of infidelity by either of the couple have also been recorded. Socialization of children, which now takes place outside the home has resulted in increased cases of deviant behaviour among children. To minimize the negative effects wrought on the family by western education, social planners must try to merge those positive elements of the traditional family with those of the modern family.
\end{abstract}

\section{INTRODUCTION}

The role of education as a change agent is indisputable, and as Lebaking and Phalare (2001) have observed, education has always been a central mechanism for transmitting of skills and values for the sustenance of societies and promotion of social change. In case of Nigeria, which came under the British Colonial rule towards the latter part of the nineteenth century, colonialism brought with it certain ways of reconstructing social reality (Labaking and Phalare, 2001) and the vehicle employed was western education.

During the colonial era which lasted between 1861 and 1960, education was a very powerful weapon for transforming the Nigerian society. As observed by Lebaking and Phalare (2001) colonial education called into questions the very humanity and essence of African people. Also called into question were many institutions and cultural practices. African religion, medical practice and the family as an institution were regarded as "traditional" and hence, were also regarded as "backward". On the other hand, orthodox western medical practices, European ways of thinking, speaking, eating and dressing were regarded as 'modern' or "progressive". The family came under serious scrutiny. Generally, "progress" was defined by how closely traditional institutions and practices were adapted to the European ways of life.

Since progress was defined by Western standards, many elements of the traditional family came under very serious attacks. Polygamy was viewed as illegal and barbaric, the extended family was regarded as tyrannical, mate selection which, hitherto was done by parents was regarded to as a violation of individual rights to choose partners and the patriarchal system was viewed with suspicion as it choked the rights of women. Progress within the family was measured by how much men and women shared the hitherto patriarchal power which had already become diffused. Change from the traditional to modern was also measured by how freely children interacted with their parents. This paper which has been inspired by an earlier work by Thadani (1978) examines the impact of western education 
on the family in Nigeria and assesses the "progress" from the traditional to the modern types. The paper commences by defining the family.

\section{THE FAMILY}

The family has been defined by Ekong (1988: 203) as a kinship group linked together by blood or marriage with members occupying a common household. Ekong further asserts that the family comprises of human elements of a man, a wife or wives and children who live under the same roof. These human elements constantly engage in interaction and they influence each other's behaviour in a more intimate manner than with others outside the family group. The family is the foundation on which the society is built and it makes the society possible by ensuring that human beings are constantly reproduced to replace the older members who may eventually die off (Strong et al., 1983: 7).

\section{The Family as a Social Institution}

The family as a social institution has formalized sets of norms and values that make living possible. It also has a set of procedures which include courtship, engagement and marriage. The family has a set of values which may include taboos, rules of descent, property ownership and others. The family as an institution has a set of roles, and statuses which define division of labour and structures of relationship between family members. The family also has a set of procedures which ensures that members perform their duties to socially required expectations. When these rules and procedures are properly obeyed, the basic foundations of social order would have been laid.

For the purpose of this paper the extended family will be operationally defined as that in which members include, blood relations like uncles, aunts and in which members are obliged to help and support one another. The nuclear family consists only of a husband (father), wife (mother) and children. In the course of this paper the extended family might also be referred to as "traditional" family while the nuclear family may be regarded as "modern" family. In other words, the terms may be used interchangeably. Western Education has played a major role in changing the family from extended to the nuclear types.

\section{The Family in a Changing Society}

As mentioned earlier, the family has not been immuned from the rapid social changes which have swept through the country in recent times. Although these changes have been engendered by the influence of western education; they have also been affected by other closely related phenomena. These include, rural-urban migration, urbanization, industrialization and modern mass communication, just to mention a few.

In the face of the rapid social changes outlined above, the extended family system has almost collapsed. Consequently, many aspects of the family system have also undergone rapid changes. For example, the relationship between husbands and wives has become redefined, parental authority has become weakened, mate selection has undergone an almost complete metamorphosis and traditional gender role relationships have become challenged. For a clearer analysis of the role of western education in accelerating these changes, it is necessary to firstly focus on the traditional family structure and later to examine the modern family system into which the traditional system has "progressed". Later the paradox of this progress will be highlighted.

\section{The Family in the Traditional Setting}

For analytical convenience it is always necessary to distinguish between the traditional and modern families. However, in Nigeria, both systems are still found to exist side by side in many communities, especially in the large urban centers with both modern and traditional sections. It is to be noted that while the traditional system predominates in rural areas, the modern system is to be observed as the most popular in the urban areas.

In the traditional setting, in Nigeria the family rests squarely and firmly on a tripod consisting of, the extended family system, patriarchal authority and patrilocal habitation and patrilinal mode of inheritance and succession. Here, the traditional family will be examined from the perspectives of structure, mate selection, socialization, and division of labour. A searchlight will then be put on how western education has affected these elements of the traditional family, in other words how these elements have "progressed" due to the factor of western education. 


\section{The Family Structure in the Traditional Society}

In many traditional families in Nigeria, most especially in the rural areas, the extended family system is still the norm for the purposes of this paper, some examples will be cited from different parts of Nigeria. In the Northern part of the country, for example, references will be made to the Hausa/Fulani family. The Hausa/Fulani constitute the major ethnic groups in Northern Nigeria. The Yorubas who represent the major ethnic group in Western Nigeria will be cited while reference will be made to the Binis and the Ibiobios who represent ethnic groups in the Midwestern and southern parts of Nigeria. References will also be made to the Igbo, also of the South-Eastern parts of Nigeria.

Common to all the ethnic groups in Nigeria is the extended family system. Among the Yoruba ethnic group of South-Western Nigeria, the extended family is based on sanguinal kinship system with the "agbo ile" (or compound) as the dwelling place which also doubles as the center of major family activities. The compound actually comprises of a flock of small houses built together (Fadipe, 1971). Each house, in turn, comprises of two or more rooms which are inhabited by each "nuclear" family. The small housing units actually adjoin each other being only separated by a common wall. The principle of the kinship system emphasizes mutual cooperation, social, physical and emotional supports.

The Yoruba kinship system attaches much importance to seniority in age. The cult of respect for elders pervades all aspects of interpersonal relationships. As mentioned earlier, the family compound is the center of all social, economic and religious activities. Division of labour is strictly along gender lines. When crucial decisions which affect the family are to be taken, women and children are usually excused. They are to be seen and not to be heard!

Under the extended family system, divorce is very rare because, whenever marital disagreements occur, the elders quickly intervene as marriage Counsellors and amicable settlements are consequently effected. Divorce is regarded as a challenge to the respect and dignity of the families of both partners, hence, all efforts are made to prevent its occurrence. Under the watchful eyes of the elders, spouse and children abuse are very rare.
Among the Binis of the Edo state, Ekong (1988) has observed that all dependants which include women and children are regarded as servants of the patriarchal head. Should the head of the family become deceased, the beneficiaries of his properly are usually his brothers and sisters with his widows having no access to his property.

The case of widows in almost all ethnic groups in Nigeria deserves special mention. When a man dies, any of his relatives or his eldest male son may inherit his widow. In many ethnic groups in Nigeria, widows go through many ordeals. These may include shaving the hairs of the widow, making her drink the water used in washing her husband's dead body, she is also made to undergo an extended period of confinement into the house, (see Aderibigbe, 1996; Afigbo, 1989). Later on in this paper, we will examine how these practices have been challenged. The next aspect of the traditional family system is mate selection.

\section{Mate Selection and Marriage Under the Traditional Family System}

In the traditional milieu, mate selection for both males and female occurs at different times of their development. For the man, male selection occurs at adolescent whereas for the female the process occurs at a slightly younger age.

At the attainment of puberty the man is expected to commence the process of finding a future partner. When the time comes the man delegates his sisters or cousins (usually women) to "scout" around for a suitable girl. Some criteria are however set before scouting commences. For example, the young girl in question must not be a blood relation, no known hereditary diseases must be traceable to her ancestors. When a young girl has been located and contacted informally through the female scouts, the next step is to contact her parents. If the parents of the girl consent, she is eventually betrothed to the young man. At this stage, the girl is usually around ten years of age.

During the intervening period between betrothal and wedding, both boys and girls are expected to maintain emotional and physical distances from each other. This is done in order to discourage pre-marital intercourse since the girl is normally expected to be a virgin until her wedding night. A girl who has been "deflowered" before her wedding night exposes herself and her family to ridicule and scorn. 


\section{Forms of Marriage}

In the traditional environment, there are usually many forms of marriage. Fadipe (1971) has identified four major types among the Yoruba. The first type is the marriage in which the mutual consents of both partners and their parents are secured. The second type is one in which the bride is made a "free gift" (which is not usually refused) to her husband who is usually a very prominent man in the community. It must be mentioned that this system is almost extinct. The third type is where both men and women get married without the usual parental consent. The last type is the levirate where a widow either becomes the wife of her late husband's eldest son (mothered by another woman) or she is inherited by an older relative. In the above examples, except where the parental consents are not sought, a marriage seals a bond between the families of both husband and wife.

In the traditional family system, it is the responsibility of all members of the extended system on both sides to ensure the success of the marriage. As mentioned earlier, the elders are marriage counselors. Couples are usually expected to commence having children as soon as marriage is consummated and family planning is not usually encouraged, because, children are regarded as social and economic assets. Marriage and child bearing are followed by socialization of children.

\section{Socialization in the Traditional Family}

The process of socialization involves the inculcation of the norms and values of the community into the child as soon as he or she is born. In all ethnic groups in Nigeria there is a strong emphasis on respect for the elders and this forms the kernel of early socialization. Even any demonstration of curiousity by the youngster through the asking of questions is seriously discouraged. Boys and girls are socialized strictly along gender lines where roles are strongly gender defined.

All members of the extended family must jointly partake of the socializing of the younger members. Whenever a child demonstrates any aberrant behaviour, it is the duty of the older members to prompt effect corrective measures. The next aspect of the traditional family system is division of labour.

\section{Division of Labour in the Traditional Family Setting}

Division of labour in the family among major ethnic groups in Nigeria is usually strictly along gender lines, Fadipe (1971) has observed among the Yorubas for example that a man and his wife do not necessarily form a complementary economic unit. While both may work on the farm engaging in the acts of planting and harvesting, the wife may decide to engage in her own tradition activities independent of the husband.

Among the pastoral Fulanis of the Northern Nigeria, there is a very strong emphasis on the separation of the sexes (Ekong, 1988). In the case of the Hausa from the same part of the country, most women are under purdah. However, the Hausa women who are not under purdah actively participate in farming activities alongside their husbands. The Hausa man is expected to provide his wife with food, firewood and other materials. Occasionally some Hausa women are to be found engaged in home based occupations like weaving, spinning and trading. In this situation the wife's earnings remain hers and any contribution from her to the running of the household is regarded as a temporary loan (Ekong, 1988) which the husband is expected to pay back later.

In the case of the Ibiobios of South-Eastern Nigeria, the man allocates pieces of land to his wife or wives for the cultivation of some food crops like cassava, yam etc. Among the Ijaws of the Southern Nigeria however, the wife is usually the breadwinner. Having examined the family from traditional perspectives, it is now necessary to examine it and the changes wrought on it by western education.

\section{Changes in the Nigerian Family as a Result of Western Education}

There is no doubt that the family like any other social institution has undergone tremendous changes due mainly to the influence of western education. Because these changes have been from the traditional to the modern they have often been regarded as "progress". The areas include, the model family structure, the size of the family, age at marriage mate selection and so on.

\section{The Structure of the Modern Family}

In contrast to the traditional setting the most 
predominant pattern of marriage, especially in the urban centers is monogamy and the nuclear family. Residence is predominantly neolocal in contrast to the patrilocal system observed in the traditional setting.

In the modern setting, there is the almost complete absence of the extended family system, although some relationships do exist in the urban areas which seem to mimic the extended family system. Here, social supports are based on a network of the relationships arising from professional, religious or political associations. These relationships offer social and psychological supports to members especially in times of adversity. Unfortunately the relationships sometimes tend to be temporary as members may change occupations, lose their jobs or relocate to other parts of the country. In such cases, the process of building these relationships are started all over again. Another aspect of the modern urban family which deserves mention is the change in the size of the family.

\section{Size of Family}

It is generally observed that the aggregate size of the average urban family is smaller than that of the extended family which is characteristic of the traditional family. For example, Olusanya (1967) conducted a study among some selected families in the metropolitan city of Ibadan which is the capital of the Oyo Stae, in Nigeria. He discovered that after 20 years of marriage wives who were educated had more children per woman than those not educated. Since the educated woman was in a nuclear family vis a vis the uneducated woman who was in a polygynous family settings, the aggregate size of the urban modern family is smaller.

Olusanya (1967) also discovered that knowledge of birth control varies directly with the educational levels of the women. Among the women with primary school education, only $12.2 \%$ indicated some knowledge of birth control compared to $42.1 \%$ for those women who had secondary or university education. Education has also played some roles as regards age at marriage.

\section{Age at Marriage}

In the modern family setting and due mainly to the influence of western education, there has been a drastic change in the age at which young men and women marry. This change has been brought about as a result of long periods of time which must be devoted to education and training (Olusanya, 1967). In a study conducted by Olusanya at the city of Ibadan it was observed that $14.3 \%$ of husbands without any western education had contracted marriage when they were still under 20 years of age. In contrast, none of the husbands who were graduates got married before they were 20 years old.

Among wives who were interviewed the following results were obtained: $28 \%$ of those without primary education got married before they were fifteen years old. Also only $1.5 \%$ of those with secondary school education got married before they were fifteen years old. However, of all the wives who were university graduates, non got married by or before they were fifteen years old.

In a similar study conducted by Callaway and Shilkrout (1987) among some Hausa women in he city of Kano, in Northern Nigeria, it was discovered that those girls who enrolled in primary schools postponed marriage beyond the traditional age of eleven or twelve years to complete their primary school education.

Incidentally postponement of marriage and childbearing due to schooling and professional training has drastically reduced some of those health hazards which are usually attributed to early marriage, especially, vestico virginal Fistula problem. Closely related to postponement of marriage is also the corresponding postponement of child bearing. Also closely tied to marriage and child birth is mate selection.

\section{Mate Selection}

No other area of the family has the role of western education been more evident than that of mate selection. This aspect of the family is so crucial because, the nature of mate selection will have a direct effect on the success or failure of a marriage. As mentioned earlier, in the traditional environment, mate selection is a joint enterprise between the families of both the concerned youngman and woman. Since both families are intimately involved in the process, the relationship which eventually results in marriage is meant to cement that between the couples' families. Generally, marriage in the traditional environment is devoid of courtship and, romantic love is usually expected to develop after the marriage has been consummated! Because the families of 
both couples were involved in the process of mate selection, it is obligatory for them to play counseling and supervisory roles in the marriage, making sure that cracks do not occur in the relationship. As stated earlier marriage is mostly endogamous and gender roles are strictly maintained, those factors that may cause divorce are minimized. Divorce, whenever it occurs is regarded as a challenge to the reputation, prestige and the integrity of the families of both husband and wife.

With the advent of western education, it became necessary for young men and women to leave their local environment purposely to go to school or to seek for paid employment, most especially in the urban areas. At school or in the place of employment boys and girls of different social, economic and ethnic backgrounds began to interact and develop romantic relationships. Today, the process of mate selection takes place between young men and women free of parental interference. This has weakened the traditional marital conventions (Hanna and Hanna, 1981).

In the school, at work or in a typical urban environment criteria for mate selection are based on achieved rather than ascribed attributes and romantic love is the driving force behind mate selection (as also practiced in the western world). Incidentally, the independence to choose one's partner has occasionally resulted in both young men and women setting some criteria for mate selection which might be difficult to meet.

Recently, Erigha and Akanni (1999: 16) interviewed some young men and women who were still single. The researchers wanted to know what attributes the respondents would like to see in the men and women they proposed to marry. The male respondents indicated that their future wives must be well educated, intelligent, responsible, homely and faithful.

The young women on he other hand would want their future husbands to be firm, intelligent, handsome, tall, rich and with a good sense of humour. None of them indicted any interest in the family medical history, or other vital criteria which would have been emphasized in the traditional mate selection process. Also, in real life, only few human beings combine all the attributes which the respondents listed. Because of the unrealistic standard which some young men and women have set for their prospective partners, finding suitable partners sometimes becomes very elusive and problematic. Because of the high and unrealistic standards indicated above, for the young men and women, finding a suitable partner sometimes becomes difficult resulting in prolonged postponement of marriage.

The men who remain bachelors above thirty years of age are usually labeled "senior boys" while their female counterparts are labeled "senior girls". The single women are regarded as nightmares to married women who regard them as husband "snatchers" (Adaeze, 2002). On occasions, some single professional women sometimes opt for motherhood by having children for married men (Akinmoladun, 2000). In some cases they also become permanent mistresses. In Nigeria a women is only fulfilled when she has satisfied the society's expectation of being a wife and a mother.

One of the consequences of people's exposure to western education in Nigeria is increase in inter ethnic marriages. Incidentally this pheno-menon has long been advocated by those who assert that such unions between Nigerians of diverse backgrounds will, over time, destroy old myths about different tribes, challenge tribal and ethnic stereotypes, reduce inter ethnic suspicions, promote intertribal cooperation and finally, result in national integration (Adaeze, 1999). However, failures of such marriages could also have many serious social consequences. It may reawaken latent intertribal prejudices, promote inter ethnic hatred and suspicion, especially where either or both parents of the young couple were originally opposed to such a union.

Finally, one area of mate selection which has undergone a drastic change is the traditional emphasis on chastity. Olusanya (1967) has observed, for example that there is a decline of emphasis on virginity as a desirable attribute in a woman. This has also been observed by Aina and Odebiyi (1997) who indicated that in the traditional African culture any woman found "wanting" on her wedding night was regarded as a disgrace to her family and clan. To protest the girl's "deflowered" status, a broken calabash was usually sent to her parents the morning following the wedding night. However, if the women was still a virgin the stained bedsheet was publicly displaced and her parents were complimented. Nowadays, many partners sometimes insist that their brides get pregnant before they contract any marriage in order to prove their fecundity. 
Aina and Odebiyi (1997), referring to an earlier demographic survey in Nigeria observed that $98 \%$ of all women $20-49$ have had sexual intercourse, the median age at first sexual intercourse being put at 16.3 years of age. They referred to another study by Oronsaye who discovered that $55 \%$ of their respondents admitted that they had had sexual intercourse by the time they were 16 years old. This situation has occurred as a result of incursion of western "civilization". The next aspect of the modern family is socialization.

\section{Socialization}

In the modern family in Nigeria parents have almost lost their places as major agents of socialization. Child minders, schools, peer groups now compete with parents as agents of socialization. In the urban centers where both parents are professionals and therefore have to be away from their children for the greater part of the day, peer group members, baby seaters may displace them as major agents of socialization.

Of particular importance is the impact of television on the modern family, most especially the children. The television is very important in keeping abreast of current events, it also exposes the child to some beneficial educational programmes. However, if television viewing by children is not closely monitored by parents, it can have very adverse effects on them. Biakolo (1993) has observed for example, that when children spend excessive time watching the television, it can result in slowing down their creative thinking, destroy their imaginative life and the time spent watching the television can eat deep into the time they need to spend doing their home work.

Television may also accelerate a child's exposure to sex and violence, it can sharpen their taste for material acquisition and acceptance of violence as a way of life. Also advertisements that portray drinking and smoking as masculine traits may have negative affect a child's socialization. There are some movies that glorify deviant behaviour as a way of life. These may also lead children to adopt deviant ways of life, the types recorded by Oloruntimehin in 1973. Another area in which western education has impacted on the family is in the area of power relations between husbands and wives.

\section{Power Relations within the Modern Family}

Exposure to western education has been observed to influence the relationship between spouses in the modern family. Lloyd (1967) for example, has observed that, in the urban family the patriarchal authority seems to have become diffused. He observes,

"They (fathers) realize that the future of their children does not depend on 'fate' or the 'will of God', but rather on the about of cooperation they give to the children to develop their initiative to express their own interest and personalities"... (178).

Because of the influence of western education on the modern family, couples are able to discuss more freely, issues that are of interest to husbands, wives and children.

In a study conducted by Olusanya (1967) which has been referred to earlier, wives were asked whether they ever discussed the number of children they desired with their husbands. 59.5\% of those who had only primary school education while $81.9 \%$ of those who had university education respectively answered in the affirmative. Power relations in the family cannot be well understood without a brief reference to the new phenomenon known as dual career family.

\section{The Dual Career Family}

The dual career family is the one in which both husbands and wives have their own professional careers. One of the most significant effects of the dual career phenomenon is the increase in the family's aggregate income. It has also led to an increase in the status of professional women within their families (Nwabara, 1987). It has resulted in the alteration of the traditional gender role expectations within the family. Woman are no more strictly tied to the roles of mother and wife. Rather they have become cobreadwinners with their husbands by sharing financial responsibilities (Zudanneck, 1987).

According to Zudanneck (1987), in a typical urban setting in Nigeria, while men may generally be responsible for rent, both men and women bear joint responsibilities for the day to day expenditure, with women occasionally contributing more to buying foodstuffs. Maintenance of the children is also a joint responsibility of both husbands and wives. In a typical urban home, while men may pay the children's school fees, 
wives spend money on baby food, provide money for pupils and take responsibility for clothing and medical care.

Common observation has also revealed that the dual career phenomenon may have adverse effects on family stability. In recent times, the harsh economic conditions have forced husbands and wives to separate, especially where one member is forced to migrate to either Europe or America in search of greener pastures to boost family income.

The forced separation indicated above consequently deprives the children the full complement of parental emotional and social supports. The mass media is full of examples of cases of infidelity on the part of either of the partners who remains at home or the ones who have gone abroad (see Asaeze, 2002).

Occasionally, for the women the dual career phenomenon may result in "role overload" (Strong et al., 1983) more so for women who may sometimes experience fatigue, irritability and a feeling of inadequacy both as a mother and a wife, the situation has been referred to as the "super woman squeeze" (Newsweek of May $19^{\text {th }} 1990$ ).

Husbands of professionally successful women may also feel threatened by their wives' success especially men whose self esteems are closely tied the fact they earn higher income than their wives (Sauti Yasiti, 1992). It has been demonstrated by Strong et al (1983) that wives who are professionals tend to wield more power within household than those who are unemployed. In Nigeria this may provide a source of conflict between the wives and their in-laws who might perceive that such influence must have roots in supernatural means employed by the wives to control their husbands.

\section{Women's Education as a Catalyst for Charge in the Family System}

The acquisition of western education has empowered women not only to challenge some traditional family practices which are harmful to women but it has also emboldened them to press for the outright elimination of such practices. Some of these harmful cultural practices which have come under severe onslaught by women include, discriminatory property laws (Laws of inheritance, laws of succession), widowhood practices and so on. The new phenomenon is observable, not only in Nigeria but also in other parts of Africa.

In the Ivory Coast for example, women's groups mobilized for the abolition of early marriages by fixing the minimum age of marriage for women at 14 and that for men at 16 (Tougana, 1997). Also, the Jacquiot Decree of 1951 was introduced as a result of pressure from women's groups. This decree afforded women the opportunity to seek divorce out of an unpleasant marriage. In a predominantly catholic country like Ivory Coast, this was a major achievement. The decree also limited the amount of bride wealth to be paid by a prospective husband.

Also, in Ghana, political activities by educated women have paid heavy dividends in form of drastic changes in marital laws. An example was the enactment of Intestate Law of Succession of 1985 (Manuh, 1997). This law abolished the stigma of illegitimacy hitherto applied by the state in which a wife and her children could be legitimate for some purposes while remaining illegitimate for others. Also, in Ghana, Akan mothers were forced to seek relief by asking the courts to place new demands on fathers of their children (Mikell, 1997). These demands led to better economic benefits for the children and it mitigated the suffering of women.

In Nigeria, women pressure groups and some non-governmental organizations (NGOS) have recently focused on many harmful cultural practices within the family, the most pervasive being the degrading widowhood practices and rites. This was mentioned earlier.

If there is any cultural practice which can be described as "man's inhumanity to man" (to "woman" in this case) it is the widowhood rites which are traditionally practiced among all ethnic groups in Nigeria, comments by Afigbo (1989), Nzewi (1989) and Ahonsi (1997) attest to the fact that when men die in Nigeria, their widows are made to undergo some rituals which are degrading to humanity. Some of these include making the widow drink the water which was used to wash her husband's corpse, shaving the widow's head, confining the widow indoors, for a prolonged period of time, and making the widow wear a black dress for a long time after her husband's death.

In many instances relatives of the dead husband may demand documents that relate to the dead husbands property (Nzewi, 1989). In some cases the widow might be ejected from her 
matrimonial home and no concrete plans might be made for the children's education. These degrading and dehumanizing practices are observable across all ethnic groups in Nigeria.

It is heartening to observe that, the widowhood practices described above have come under powerful searchlight and very devastating criticisms in the past few months. An organization called widowhood in Nigeria Network (Wini-Net) has been in the Vanguard of the above activities. In the Nigerian Tribune of October $18^{\text {th }}$ 2002, it was reported that an organization, Loto production was calling for the enactment of new laws to protect the widows. Akanbi (2002) asserts that Edo, Enugu, Anambra and Ekiti states in Nigeria have introduced legislations that would eventually alleviate the suffering of widows in Nigeria. Those at the vanguard of pushing for a change in these barbaric widowhood practices have been able to do so, due to exposure to western education.

This paper having examined the family in both the traditional and modern settings has indicated the overarching influence of education on the family as it progressed from the tradition to the modern states. This change has given rise to some of the paradoxes discussed below:

\section{DISCUSSION}

The history of western education dates back to the latter part of the $19^{\text {th }}$ century when the British initially introduced their colonial rule in Nigeria. The first university was established in Nigeria (University college, Ibadan, now University of Ibadan) in 1948. Today, the country boasts of about forty universities, over six thousand secondary schools and over thirty nine thousand primary schools (Annual Abstract of Statistics, 1999). Thus, the impact of western education is very pervasive and its effects are felt in all social institutions including the family.

Due to the impact of education the family has "progressed" from the traditional to the modern. Some of the elements of the family which have been greatly affected are highlighted below.

The extended family system with its almost tyrannical hold on its members has given way to the nuclear family system where members are only responsible to their immediate family members. There is freedom in mate selection and men are no more imposed on young girls.
Socialization of the young is no more the joint enterprise of the elders of the extended family who maintain a constant surveillance on the young. The burden of maintaining the family is no more borne by the father/husband alone but it is made lighter because the mother/wife also shares in it. The erstwhile position of the husband who has an authoritarian hold on the wife and children has given way to that in which there is democratization of decision making between husband and wife since both of them are likely to be professionals who jointly support the family with their incomes.

Although the changes above connote and give an appearance of progress, further examination however reveals that they have their paradoxes. For example, the gradual demise of the extended family system also means the loss of social, economic and emotional safety nets. The loss of the watchful eyes of the members of the extended family means, that individuals within the nuclear family system could indulge in child or spouse abuse without immediate reprimand.

The progress recorded in form of freedom to choose one's spouse is almost neturalized by some other problems. Modern mate selection process is usually initiated by dating. During the period of dating, couples may well engage in impression management where the actors may not really discover the true identity of each other until they start to live together after the wedding. Also in the new arrangement, couples may not have access to marriage counseling. Modern marriage is also bedeviled by high divorce rate and its negative consequences. Many pro-fessional women remain single having children out of wed lock.

In the modern family, parents may not have enough time to spend with their children due to the pressure of paid employment. Socialization is thus carried out by peer groups, child minders and the mass media. This has resulted in increased incidence of juvenile delinquency and crimes of all kinds.

Although the dual career marriage may have resulted in higher income for the modern family, wives who earn higher income than their husbands may be perceived as threats by those husbands whose self esteems are closely tied to their earnings which are superior to their wives. On occasions where one spouse is separated from the other due to professional mobility cases of infidelity may result and loss of care for the children may also be a consequence. 


\section{CONCLUSION AND RECOMMENDATION}

The influence of western education is very pervasive in all social institutions in Nigeria. The family is no exception. This influence is particularly evident in improved techniques, of birth control, child birth, immunization and child nutrition. This situation cannot be reversed. As we assess progress in terms of western technology and science it is also necessary to measure progress by taking a critical look at the social aspects of the family. To minimize the negative impacts of western education on the family it is very important to retain some aspects of our traditional culture which impact positively on the family.

The extended family system must not be allowed to be totally corroded by the adoption of western culture. In Nigeria where there is a conspicuous absence of social welfare programmes by government, the extended family must be encouraged. This will provide social, economic and emotional safety nets for people. In the urban areas, membership of voluntary associations must be encouraged to cater for the physical, material and emotional needs of individuals. Recently, Ajayi (1999) has observed that a team of Americans who had visited Nigeria were impressed and fascinated by the extended family system. They promised to advocate for its revival on their return to the United States. Incidentally such revivals are taking place in medicine where traditional medical practitioners operate side by side with their western counterparts.

In the areas of mate selection and marriage, marriage counselors should be trained to provide advice and counseling to prospective couples and those having marital problems. Parens must monitor their children and inculcate in them, respect for elders and consequently, for constituted authority. Efforts must be made to provide adequate supervision for children so that effects of negative peer pressure and influence might be minimized.

The Nigerian governments at Federal state and local levels must continue to effect poverty alleviation programmes. These will reduce stress within the family and eliminate feelings of insecurity.

Finally, if the gains of western education are to be maximized, more concrete steps must be taken to tease out those positive aspects of our traditional practices and integrate them with those of the modern western culture. Efforts must also be made to educate the citizens on those harmful cultural practices which are incompatible with the modern family institution.

\section{REFERENCES}

Adaeze, Amos: Intern Tribal Marriages can curb Tribalism - Mrs. Njdeka Ezeffe. Sunday Punch, Sept. $5^{\text {th }}, 19$ (1999).

Adaeze, Amos: Help: An Asian Woman has 'stolen my husband': Sunday Punch November $3^{\text {rd }}, 36$ (2002a).

Adaeze, Amos: Senior girls and their 'tonies': Sunday Punch October $13^{\text {th }}, 37$ (2002b).

Aderibigbe, T. :Legal Rights and Constraints for Women's Empowerment. In: L. Erinosho, B. Osotimehin and J. Olawoye (Eds.): Women's Empowerment and Reproductive Health. Social Sciences and Reproductive Health Research Network, Ibadan (1996).

Afigbo, A.E.: Widowhood, Practices in Africa: A Preliminary Survey and Analysis. In: Proceedings of the Better Life Programme for Rural Women Workshop on Widowhood Practices in Imo State, Oweri Government Printer June 6 - 7 (1989).

Ahonsi, B.: Society Culture and the Status of Widows in Contemporary Nigeria: A Gender Analysis and Prospects. Lagos Friendrich Ebert Foundation, Lagos (1997).

Aina, O.I. and Odebiyi, I.: Transmission of Poverty: Experiences Unmarried Adolescent Mothers in Osun State, Nigeria. A Study for Union of African Population, 15 and 21. (1997).

Ajayi, Ade: Nigerian extended family system admirable: American team. Daily Monitor, August 27 ${ }^{\text {th }}, 5$ (1999).

Akanbi, Festus: Oyo urged to protect widows' right. Sunday Punch, October 20 ${ }^{\text {th }}, 15$ (2002).

Akinmoladun, Taiwo: My mother is my father. Sunday Tribune, Feb. $6^{\text {th }}$, p. 17 (2002).

Annual Report of the Federal Office of Statistics, Lagos, Nigeria (1997, 99).

Biakolo, Emerwo: Television and the family: A review. The Guardian, March $13^{\text {th }}, 15$ (1993)

Callaway, Banbara and Sullroit, Enid: Law, education and social change: Implications for Hausa Muslim women in Nigeria In: Lynn B. Iglitz is and Ruth Rose (Eds.): Women in the World 1975 - 1985: The Women's Decade. ABC CLO Press, Santa Barbara, California (1987).

Ekong, E. Ekong: An Introduction to Rural Sociology. Ibadan Jumak Publications, Ibadan (1988).

Erigha, Agness and Akanni, Dayo: Single girls everywhere: Nigerian Tribune on Sunday, Sept. $5^{\mathrm{t}}$, 16 -17 (1999).

Fadipe, N.A.: The Sociology of the Yoruba. University of Ibadan Press, Ibadan (1971).

Lebaking, Teboha, J. and Mina Batho, M. Phalare: Africanisation of the social sciences within the context of globalization. Codestra Bulletin, Nos 3 \& 4: 23 - 25 (2001).

Lioyd, Peter: African in Social Change. Pengum Books, Middlesex (1967).

Manuh, Takyiwua: Wives, children and intestate succession in Ghana. In: Gwendolyn Mikelli (Ed): African Feminism: The Politics of Survival in SubSaharan 
Africa. University of Pennsylvania Press, Philadelphia (1997).

Mikilli, Gimendolyn: Please for domestic relief: Akan women and family courts. In Givendolyn Midelli (Ed.): African Feminism: The Politics of Survival in SubSaharan Africa. University of Pennsylvenia Press, Philadelphia (1997).

Newsweet May $19^{\text {th }} 1980,72$ - 79 (1980).

Nigerian Tribune May $7^{\text {th }} 1999,23$ (1999).

Nigerian Tribune Oct. $18^{\text {th }}$ 2002: 1 (2000).

Nwabara, Comfort O.: Women and Work in Nigeria. Paper presented at a Seminar on Women's Studies; Institute of African Studies, University of Ibadan, November 4- 6. (1987)

Nzewi, E. :Widowhood practices: A female perspective. Proceedings of the Better Life for Rural Women Workshop on Widowhood Practices in Imo State. Owerri, Government Printer, June 6 - 7 (1989).

Oloruntimehin, O.: A study of juvenile delinquency in a Nigerian city. British Journal of Delinquency, 3: 157 169 (1973)
Olusanya, P.O.: Educational factors in human fertility: A case study of the residents of suburban area in Ibadan. Nigerian Journal of Economic and Social Studies, 9(3): 251 - 374 (1967).

Sauti Ya Siti: Tanzanian Women's Magazine November (1992). Strong, Bryan, Vault, Christian De, Said, Murray and Reynolds, Rebecca: The Marriage and the Family Experience. West Publishing Company, St. Paul Minnesola (1983).

Thadani, Veena: Women in Nairobi, the paradox of urban 'progress'. African Urban Studies, 3(57): 67 - 83 (197879).

Tougara, Jean Maddox: Changing the meaning of marriage: Women and family law in Cote d'Ivoire. In: Givendolyn Mikelli (Ed.): African Feminism: The Politics of Survival in SubSahara Africa. University of Pennsylvania Press, Philadelphia (1997).

Zudanneck, Gabriel: The Work Women in Urban Labour Market. Paper presented at a Seminar on Women Studies Women and Work in Nigeria: Institute of African Studies, University of Ibadan, November 4-6 (1987). 